\title{
Is It Possible to "Incorporate" a Scar? Revisiting a Basic Concept in Phenomenology
}

\author{
Jenny Slatman ${ }^{1}$
}

Published online: 18 February 2016

(C) The Author(s) 2016. This article is published with open access at Springerlink.com

\begin{abstract}
Although scars never disappear completely, in time most people will basically get used to them. In this paper I explore what it means to habituate to scars against the background of the phenomenological concept of incorporation. In phenomenology (Husserl, Merleau-Ponty) the body as Leib or corps vécu (lived body) functions as a transcendental condition for world disclosure. Because of this transcendental reasoning, phenomenology prioritizes a form of embodied subjectivity that is virtually dis-embodied. Endowing meaning to one's world through getting engaged in actions and projects is most successful indeed when one's body is "absent," "transparent," or, at least, if it is not in the center of one's attention. This taken-for-granted nature can be disturbed by discomfort, disability, and disfigurement. Incorporation, so I explain, aims at maintaining or restoring the body's taken-for-grantedness. My analysis of the case of a woman who successfully habituated to her mastectomy scar demonstrates, however, that habituation to a perceptible scar can only be understood partly in terms of incorporation. Next to a decrease of explicit attention for the scar and the discomfort it produces (i.e., incorporation), the scar should also stop being a sign that refers to something else than itself. This is only possible, I argue, by taking the body's materiality seriously, rather than it being wiped out as a result of transcendental reasoning.
\end{abstract}

Keywords Incorporation · Habituation · Mastectomy scar · Husserl · Merleau-Ponty · Nancy

Jenny Slatman

Jenny.slatman@maastrichtuniversity.nl

1 Department Health, Ethics and Society, Research School CAPHRI, Maastricht University, PO Box 616, 6200 MD Maastricht, The Netherlands 


\section{Introduction}

Reflecting on his own marked and aged body, the novelist Auster writes that scars are "letters from the secret alphabet that tells the story of who you are" (2012: 5). Indeed, scars are marks of something that has happened to your body and as such they refer to something in the past. But they also incarnate the body's present meaning in the sense that they can represent bodily difference. This is especially the case when they produce disfigurements or disability, such as in burns, facial lesions, and amputations. Aside from being a reference to what happened to one's body, these kinds of scars also involve a clearly perceptible physical change. In that sense, they may give rise to stigmatization and may thus necessitate some sort of "stigma management" (Goffman 1963), such as concealing scars by clothes, make-up, or a cosmetic device. These props, certainly, can help a scarred person to pass for normal in social interaction, but they cannot wipe out the fleshly carving on and of a person's body. Such a carving may fade out in time, but it will never vanish completely. Still most people will get used to them, to a greater or lesser degree, over a certain period of time. In this paper, I will concentrate on the question of how to understand this habituation to one's own body being perceptibly engraved. Because I am primarily interested in lived experiences of being scarred I will tackle this issue from a phenomenological angle, and will bracket the question of which actions and behavior may facilitate "passing as normal," and which may not.

If we consider the scar as a reference to something in the past, habituation to the scar means that what happened in the past got successfully integrated in a person's story, as Auster writes. If a scar produces perceptible bodily difference, habituation to it also requires familiarization with physical change. Habituation, then, involves a kind of re-identification with one's changed body. In this paper, I would like to explore how this process of getting familiar with physical change takes place, while interpreting a case of successful habituation to a mastectomy scar. Whereas a scar may initially trigger explicit awareness of one's own body, frequently in combination with a negative valuation, a scar to which one has become habituated is commonly experienced in a different way. Habituation to a physical change such as a mastectomy scar, in other words, involves a change in one's embodied selfexperience. In phenomenological terms, habituation to a scar implies a certain shift in the way one endows meaning to one's own body. To specify this shift in meaning, which goes together with a shift from being in the focus of one's attention to being in the background of one's consciousness, mainstream phenomenology usually applies the concept of "incorporation". In this paper I will discuss this concept's strengths and limits for understanding habituation to a mastectomy scar.

Women who have had a mastectomy, generally after the diagnosis of breast cancer, have a horizontal scar on their chest wall. This line, sometimes straight and sometimes irregular (depending on the condition of the underlying tissue and on the wound's healing process), marks the spot where once was a breast. A mastectomy scar, similar to other amputation scars, thus produces both physical change and physical loss. It is rather common for women who have undergone mastectomy to use the word "scar" to refer to both the visible scar tissue and the absent breast 
(Manderson and Stirling 2007). In my analysis I will address both aspects by exploring what it means to grow familiar with physical change and physical loss.

A mastectomy is commonly seen as a procedure that causes a crucial bodily difference, especially because breasts are considered as "the daily visible and tangible signifier [of a woman's] womanliness" (Young 1992: 215). A mastectomy causes a serious disruption of this powerful signifier. Against prevailing norms of feminine embodiment, a mastectomy scar becomes the marker of a hideous abnormality. Because it is hardly a self-evident matter that women with a mastectomy scar grow accustomed to such a disruption of meaning, they are advised (and sometimes urged) to take measures in order to conceal the scar, such as using an external prosthesis or having a surgical reconstruction. Whether these kinds of concealment practices always contribute to the habituation process is a contested issue. Opponents of concealment practices claim, often on the basis of their own lived experience, that these practices actually prevent women from getting used to their changed body (Lorde 1980), and that women should opt for a "false breast" only after having grown accustomed to the scar (Friedeberger 1996). ${ }^{1}$ In this paper I will not directly engage in the normative debate about what mastectomied women should do in order to come to terms with their changed bodies. Rather, I will start from the case of a woman who holds that she succeeded in habituating to her scar, and then explore how to interpret and conceptualize the phenomenon of habituation.

\section{The Case of Ann}

The case I will present here is that of "Ann" (age 68), who had a mastectomy of her left breast in 2012. Ann was one of nineteen respondents I interviewed within the context of my philosophical empirical study on how women respond to scars after breast surgery. ${ }^{2}$ While the qualitative analysis of its empirical data is presented in another paper (Slatman et al. 2015), I have chosen to reuse and further explore the case of Ann in this theoretical article because as one of the few respondents she was very explicit about the theme of habituation.

Ann underwent a mastectomy after having been diagnosed with an early stage breast tumor. Because of the size and the early stage of the tumor, Ann could choose between two treatment options: either a breast-saving treatment together with radiotherapy or a mastectomy without radiotherapy. According to current medical

\footnotetext{
1 This debate on the question whether mastectomied women should conceal their scars or not to get accustomed to their changed bodies shows that we need to make a distinction between, on the one hand, concealment management which may help women to pass for normal and, on the other hand, the experience of being habituated to the scar. In this paper I will only concentrate on the experience of habituation; I will not explore in what sense successful habituation and successful stigma management are related to one another.

2 All respondents for this study were recruited through the mamma-care outpatient clinic of Maastricht University Medical Center, The Netherlands. Ethical clearance for this study was obtained from this hospital's ethical review board, and all respondents have given their written consent to participate in it. To protect their anonymity I used pseudonyms. To grasp the temporal process of habituation, I held several interviews with all respondents. With Ann, I had two interviews, both following her surgery: after four weeks and after five months.
} 
standards, both treatment options are comparable with regard to effectively curing the cancer and preventing possible relapses. With regard to cosmetic outcomes and the size and nature of the scar, however, the two surgical treatments are fairly dissimilar. Although her surgeon advised her to take her time before making her decision, Ann almost instantly decided to go for the mastectomy: "I had a week to ponder on which treatment to choose ... When riding our bikes home from the hospital, my husband said: 'Just take your time to reflect on it.' 'Oh,' I said, 'I decided already,' and that was even before we were home".

Although her decision was a quick one, Ann said that it was well-informed rather than intuitive. As the surgeon had informed her, radiotherapy could cause burns on the skin, as well as affect her lungs and heart. Ann, a very health-minded person who had never seen a doctor in hospital before, said she wanted to minimize the risk of contracting other kinds of health problems and therefore she did not want to undergo radiotherapy. After voicing her preference for the mastectomy, she was offered the possibility to get a reconstruction. Because she lacked sufficient abdominal tissue, breast reconstruction with her own tissue was no option. Another possibility was getting a silicone implant. But as she had a strong aversion to artificial elements in her body, she quickly determined not to have any surgical reconstruction. Ann emphasized that she was well aware of the physical and cosmetic consequences of her treatment decision, offering the following selfassessment: "Well, I said to myself, I'm 68 and I think I'll manage to live without that breast". Her decision, as Ann realized, more or less implied that she would have to accept and get used to her scar. As she put it: "You have to settle on it and then get over with it. And if you are unable to do so, you should have chosen otherwise". As a matter of fact, the explicitly articulated views of Ann about how to deal with her scar, as well as with her changed body, provide a rich source for a phenomenological analysis of habituation.

\section{Phenomenology of Health and Illness and the Primacy of the Virtually Disembodied Body}

In contemporary studies on health and illness, phenomenology is often used to criticize medicine's instrumental and objectifying view on patients' bodies. Whereas medicine, generally speaking, considers patients' bodies as things, objects, or defect machines that can be repaired, phenomenologically oriented studies show that experiences of health, or able-ness, and of illness and disability cannot simply be reduced to physical "normality" or "abnormality". Phenomenology of health and illness therefore claims that we should also take into consideration patients' lived experiences of their bodies (Carel 2011; Leder 1992; Svenaeus 2009; Toombs 1995; Aho and Aho 2009; Zaner 1981; Martiny 2015; Bullington 2013). Accordingly, the majority of present phenomenological studies on healthy, ill, able, and disabled bodies fall back on the distinction between the objective body (Körper) and the lived body (Leib). If we look closely at the classical descriptions provided by Husserl and Merleau-Ponty we see that they present the idea of an embodied subject which, rather paradoxically, is as disembodied as possible. As I 
will explain later on, habituation in terms of "incorporation" derives from this idea(l) of embodied subjectivity.

Husserl writes in his Ideas II (1952: §§ 36-38) that whereas Körper refers to the meaning of one's body in terms of an intentional object, i.e., an object perceived and apprehended through an array of adumbrations (Abschattungen) and to which one may attribute physical features, Leib refers to the meaning of one's own body as a "non-thing" (Waldenfels 1989), a non-intentional experience of one's own body localized in one's body, in one's sense organ. In an earlier section of Ideas II, Husserl described the Leib as the "organ of perception" (Wahrnehmungsorgan), which is the medium (Mittel) of all perception, and which is necessarily involved in all perception (ist bei aller Wahrnemung nowtwendig dabei) (1952: § 18). So, according to Husserl, the Leib forms the condition for the possibility of perception. In contrast with Kant, he thus maintains that rather than the so-called pure forms of intuition (the forms of time and space) it is the existence of an organ of perception that conditions the appearance (Erscheinung) of spatiotemporal things.

Most typical about the Leib is that it is caught in a circle of constitution: it is constitutive for perception in the sense that no perception can take place without it, but it is also itself constituted, which means that it is not pre-given as a nonexperienced structure. Rather, the Leib is constituted by means of sensorial experience. It is thus a constituting-constituted structure. In phenomenological discourse this means that the Leib not only conditions appearance, but also appears itself, albeit in a typical way. As Husserl explains in $\S 36$, the Leib is constituted through localized sensations that he calls "sensings" (Empfindnisse). These localized sensations are materialized mainly by the senses of touch, warmth, cold, proprioception, kinesthetic sensations, and pain. On the basis of these "sensings," one's body does not appear as a thing in adumbrations, but merely as an embodied "here" and "now," a zero-point for all movement, orientation, and perception.

It is this idea of Leib as the embodied, non-formal, condition of world-disclosure that has become a central idea in Merleau-Ponty's Phenomenology of Perception, where it is called the subject body (corps sujet), the lived body (corps vécu), or one's own body (corps propre). In his early work, Merleau-Ponty writes that it is especially by means of motor intentionality that the "transcendental" embodied subject discloses its world. While thus revealing the power of sense-making inherent to embodied movement and action, he twists Husserl's idea of the Leib's faculty (ich kann) (1952: § 38) into an existential "I can" (je peux) (Merleau-Ponty 1945: 137), going along with existential philosophy's discourse of having possibilities; of being engaged in activities and projects; of being a "thrown projection" (geworfener Entwurf), as Martin Heidegger (1927) would have it; or of being free, of nothingness (néant), as Jean-Paul Sartre (1943) would put it.

The interesting premise underlying the idea of "I can" is that the range and scope of possibilities - the strength of the "I can"-seems to increase proportionally to the degree in which one forgets about one's own body. The taken-for-granted nature is one of the most powerful features of the lived body as source of agency. It is because most of the time our body is not in the focus of our attention that we can attend to the world in a successful way. In current phenomenological studies on health and illness this reverberates in the idea that the least the body is present, the 
healthier and the more capable it is. Impairments, pain, and unwanted physical changes automatically draw one's attention to one's body, which leads to what Ahmed (2006) calls a "queer" experience; the body that is supposed to be the prereflective, virtually unnoticeable point of orientation becomes itself a focal point of attention. Such a "queer" experience thus interrupts the flow of attention that was directed to a certain activity in the world, and hence inhibits one's "I can". The impact of illness, impairments, pain, and disfigurements precisely consists in undermining the body's taken-for-granted nature, causing bodily discomfort and alienation (Svenaeus 2009; Toombs 1995; Zeiler 2013; Williams 1996; Ucok 2005).

From this phenomenological perspective, habituation to physical changes, such as a mastectomy scar, can be explained in terms of "repositioning" the body to the margins of one's consciousness. This process, according to which the present body fades into the background, is called "incorporation" in phenomenology.

\section{Incorporation and Its Metaphors in Phenomenology}

According to its etymology, "incorporation" refers to the activity of putting something into the body (or substance of something else) or uniting into one body, and it is derived from the Latin verb incorporare, whereby the Latin in means "into, in, on, upon" and corpus means "body". Incorporation thus literally means combination, fusion, and annexation. For this reason, the notion of incorporation is often used to describe the relation between (human) bodies and technological devices and tools - devices that can be worn, attached to or implanted in the body in order to increase its functions and capacities (Campbell et al. 2007; Carijó et al. 2013).

In phenomenology, however, incorporation is not just about the relation between one's own body and the added element. It rather indicates a specific kind of experience. Studies that seek to articulate the experience involved in incorporation (e.g., Murray 2004; Morris 2002; De Preester 2011; De Preester and Tsakiris 2009) habitually draw on Merleau-Ponty's (1945) analysis of habit in relation to the "body schema" and to Heidegger's (1927) analysis of tool usage. The body schema, Merleau-Ponty explains, refers to one's body's unity. It is because of one's body schema that one's body is given at once. It provides an immediate knowledge (savoir immédiat) of your own body in the sense that you do not have to reflect on where your arms and legs are, or, for those who once learned how to ride a bicycle, that you won't have to pay any attention to how you should move your legs. Significantly, Merleau-Ponty stresses that the body schema is something dynamic rather than static. It is by means of habit acquisition that the bodily schema adapts to tasks and projects in the world.

To explain how habits come into being, and eventually get settled, MerleauPonty describes skills acquisition and the use or handling of tools and instruments in terms of incorporation. He writes: "A movement is learned when the body has understood it, that is, when it has incorporated it into its 'world"' (1945: 139). And "[i]t is literally true that the subject who learns to type incorporates the key-bank space into his bodily space" (1945: 145; my emphasis). As these two quotes 
concerning skills acquisition underscore, "incorporation" does not refer to a literal assimilation of two substances, as a literal meaning of "incorporation" would suggest. "Incorporated in its world, in its space" does not literally refer to an extension in this space or world. It rather means that the learned movement or skill is mastered (that "I can" do it) - that it has become part of the body schema's immediate knowledge. Incorporation implies that an acquired skill has become part of one's "habit-body" (Merleau-Ponty 1945: 82).

If we look at the use of tools and instruments, the notion of incorporation appears to have a double meaning: it refers both to a certain degree of mastering one's space and situation, and to the relation with something that extends the body: "To get used to a hat, a car or a stick is to be transplanted into them, or conversely, to incorporate them into the bulk of our own body" (Merleau-Ponty 1945: 143; my emphasis). While using a stick or cane, for instance, we do add something to our body. A blind man using a stick involves an assimilation of two things: his body and the stick. We only speak of incorporation in this case, however, if "the blind man's stick has ceased to be an object for him, and is no longer perceived for itself" (Merleau-Ponty 1945: 143). If, by contrast, a blind man is holding a cane in his hands, and is occupied with the physical qualities of the stick, its smoothness and fineness for example, the stick is not incorporated. The stick becomes incorporated if it stops being a stick with physical qualities, i.e., if it stops being an intentional object for the blind man.

In Heideggerian terms we could say that incorporation of the stick refers to a change of the stick's "meaning of being," from being "present-at-hand" (Vorhandensein) to being "ready-to-hand" (Zuhandensein). For Heidegger this shift in meaning goes together with a shift of attention from the thing at hand (the hammer) to the project in which the thing is involved (hammering). Drew Leder explains this in terms of experiential "disappearance" (1990: 33). In a way, incorporation causes the stick (or hammer) to be no longer perceptible as stick (or hammer) as such. It is therefore that Don Ihde (1990), an American philosopher of technology, uses the term "transparency" for our "embodiment relations" to technology and technological devices. To illustrate this he refers to the usage of glasses. A person wearing glasses perceives the world, and ideally, does not perceive his or her glasses. While being directed to the world, he or she sees it through his or her glasses. In the ideal case the glasses are completely incorporated, and this person will totally forget about them.

This ideal state of transparency or forgetfulness, however, can only be reached if one first actively focuses on the device or skill that needs to be incorporated. Even though this focus does not require any cognitive representation (Dreyfus 2002), the requirement of such a focus indicates that throughout a process of incorporation there can be an oscillation between background and foreground experiences of the tool or the skill. Also, once a tool or skill has been totally incorporated, it can always re-appear as an intentional object and, as a result, lose some of its transparency. Let us now turn to Ann's case and explore what kind of foreground and background experiences we can distinguish in her story. 


\section{Habituation to a Mastectomy Scar}

As pointed out previously, Ann reported very clear ideas and feelings about habituating to her mastectomy scar. After having deliberately chosen against breastsaving treatment and in favor of breast amputation, she considered habituation to the scar a requirement logically following from her decision. Interestingly, she not only said things related to her wish to habituate to the scar, but she also indicated in what sense she actually succeeded in this. Interpreting her post-surgical narrative, I identified three different registers of habituation: (a) inhabiting new habits while avoiding discomfort; (b) deliberately attending to the scar; and (c) sharing and displaying the scar.

(a) In the first weeks after surgery, Ann's scope of action was rather decreased because of pain caused by the fresh scar. After several weeks of wound healing she could resume most of her daily activities, yet with the exception of stretching her left arm because the scar was very tight. Apart from this physical discomfort, which she attempted to overcome by doing exercises and massaging her skin, she struggled with the hassle of wearing an external breast prosthesis. Having decided against surgical reconstruction of her breast, she still wanted to (or felt she needed to) conceal her physical loss and asymmetry (at least in public places), and therefore she used such a device. According to the standard procedure, Ann received a soft breast pad in the hospital the day after surgery (a pad filled with cotton). After about 6 weeks, when the wound had healed sufficiently, she was allowed to purchase a silicone pad that fits into a special bra. In the first interview she told me about having the pleasant experience that she forgot about her prosthesis:

Well, my prosthesis [the cotton-filled pad] is okay, but I have to tell you, honestly, I find it horrible to feel the thing; it does not feel nice, and I always feel it. But sometimes you forget about it. Last Sunday I went out with my husband ... and when we were back home, I caught myself not having checked a single time whether the prosthesis was still in the right place ... Well, in the beginning you are constantly checking whether it is okay, and whether other people would not mention it. But at that point, I thought, "hey, I did not check one single time". (1 month after surgery)

In the second interview Ann told me that although she bought a silicone pad, she also continued using the lighter cotton-filled pad, which actually should only be used directly after surgery, when the scar tissue has not yet sufficiently healed. She told me she preferred using the lighter pad because she is rather small-breasted. According to her, the only advantage of the silicone pad was its tighter fit; it would "stick" to her body when, for instance, bending forward. Although the prosthesis did not draw her attention very much, as she said, she did not like to wear it; she found it a bit of a fuss to wear a bra anyway, and she also noticed that the pad never totally fitted: 
I still find it does not have a nice fit, but, well, I have always hated to wear a bra. ... But this is simply how I see it, and it is also moving to and fro all the time; even though it is a tight fit, it always slides a bit. If I take off my T-shirt at night, I notice very often it has moved to the right side .... Well, I do not really feel that, and perhaps no one would see it, I believe. Unless you are completely absorbed by it; but luckily I'm not like that. (5 months after surgery)

(b) Whereas her growing familiar with the prosthesis was entangled in daily activities that largely took place without much reflection and attention, quite deliberately Ann also attended to her own body to facilitate habituation to the scar itself. Ann was, as part of her choice for a mastectomy, determined to get used to her scar. As she explained:

From the beginning I have decided to look at it [the scar] frequently. To get used to it, and to see how it changes, and note that it becomes prettier, so eh, therefore I do not wear a prosthesis when I am at home. ... And I must say that I get used to it. Well of course every morning in the bathroom I'm confronted with it. Or when I have to get changed or something, and eh, yes, it becomes prettier now the wound has healed, but obviously it remains awfully nasty.... My husband also looks at it more often, yes, yes. (1 month after surgery)

Ann underlined she did not simply want to wait for time's soothing effect, but considered the process of habituation as something she had to pursue actively. She thus claimed agency about her own body, and about her own healing process, refusing the role of victim. Looking at her scar, and engaging her husband to join her while looking at it, helped her to get used to it. In the second interview, 4 months later, I asked her whether she still looked at her scar in the mirror. She claimed to be doing that every day, assuring me that she was quite able to look at it. When I subsequently asked whether this had changed over the last months, she replied:

Well, yes, in the beginning, I was constantly looking [at it], and then I saw that, well, eh, there is nothing there now; there is only a big scar, and that is really strange. It really looks weird; on the one side I have a breast and on the other side there is nothing. But if I look at it now, I just see a body .... I do no longer mention it; I mean specifically, that the breast is no longer there. Well you do mention it, but not in the sense that it concerns me in that way. And I must say, I'm really happy that it works that way for me, because the other day I read a story about a woman who was still afraid to look at, eh, her amputated breast almost a year after surgery. If that were the case for me, I would find it very difficult. I would have a very hard time. (5 months after surgery)

As this quote reveals, a remarkable shift occurred in the way Ann experienced her scar. Whereas she experienced it first as that which underlined the loss of her breast, after a couple of months she no longer noticed this loss as such. Put differently, her experience of lack and loss had diminished. Instead of a body 
lacking a breast, her body evolved into a one-breasted body. Interestingly, this shift in experience and meaning was instigated by her active and deliberate inspection of her own scar-not because she forgot about the scar.

(c) Ann's way of dealing with her own body and the fact that she experienced a change in her perception of the scar was not a matter of two separate processes; rather, both were embedded in what I would call her bodily social practices. She and her husband were used to nudist bathing and recreation, and also liked to go to the sauna. In that sense, they were used to share their bodies' nakedness with others. In the first interview, she told me about her own experience, many years back, of meeting a one-breasted woman at a nudist site, which also made her believe that nudist recreation makes it easier to put things into perspective:

What I found really very nice, or, well, nice, [is something] that happened thirty years ago or so, when I was staying at a campground in the South of France. There I saw a rather big woman, well-stacked, who had only one breast. She walked around the site [nakedly], free as a bird. I remember thinking way back then: that's a nice way to do it. Well, you know, you look at it [her scar], you've seen it once, and that's it. I think that if you are used to nudist recreation, you are also more used to putting these things into perspective. (1 month after surgery)

In the second interview Ann told me about her experience of resuming her habit of nudist swimming after her breast amputation:

Yes, I found it really difficult to go (to the nudist beach). I went in the afternoon, but even though I had decided to go, I still had my doubts. Before I actually went, I lingered for a while: "shall I go or not?" Eventually I went. And, well, I have an acquaintance who is also one-breasted. She has been living with it for 3 years now. Coincidentally she was also on the nudist beach that day, which I didn't know beforehand. So yes, I felt that they, she and others who knew about my situation (and the news had spread like wildfire), took really good care of me. That was really nice ... She [this other woman] has been one-breasted for years. What I find funny about it is that when I talk to her now I do not see it [the scar] anymore. Actually, it has been this way for me a long time already. You talk to each other and you do not look at how this woman ['s body] is "constructed". Oh, well, you just don't see it anymore. (5 months after surgery)

She felt supported while being surrounded by like-minded people at the nudist beach. But what is also interesting here is that she noticed how she got used to this other woman's scar and did not notice it any longer as such. Like her own scar's fading, the scar of this befriended woman gradually disappeared in front of her eyes. In a way, Ann's habituation to the other woman's scar ran parallel with her growing familiar with her own scar.

Summarizing Ann's claims about her getting along with her scar, it is safe to argue that she managed exceptionally well to grow accustomed to her changed 
body. She was also very explicit about preserving her embodied agency, maintaining in the second interview: "I am not impaired at all. With one breast I can do the same things as with two breasts" (5 months after surgery). Her case is rather extraordinary, perhaps, because the majority of women may well experience far more difficulties after a mastectomy (e.g., Manderson 2011). This is not the point I would like to make here, however. Ann's case involved successful habituation indeed, but we now have to examine whether and to what extent this habituation can be understood in terms of incorporation.

\section{Habituation as Incorporation}

We can use the concept of incorporation to explain the first register of habituation, i.e., the register of inhabiting new habits while avoiding discomfort. Ann sometimes completely forgot about her prosthesis. At these moments, the device was no longer an object of attention; it had "disappeared" (Leder), or had gained a certain degree of "transparency" (Ihde). This forgetfulness was beneficial for Ann's "I can" in the sense that, at that moment, she did not bother about her breasts, but simply engaged in the things she liked to do. Brought to the background of her awareness, the prosthetic device had become incorporated; it had become part of her "body schema". However, as we have seen, most of the time it did not vanish into the background of attention. Even though Ann assumed the habit of wearing the prosthesis, it is questionable whether it had become an integral part of her "habitbody". Now and again, the prosthesis gained her attention because it did not fit well. Even though she did not really like this, as she pointed out, she was not really bothered by it. She more or less reconciled herself with the situation. Evidently, she grew accustomed to using the prosthesis only in part by means of its actual incorporation.

It is due to inadequate design of the technological device, or at least, due to an inadequate fit between Ann's body and the prosthesis that the prosthesis constantly reappeared as an intentional object. I would therefore explain Ann's prosthesis use in terms of "unsuccessful incorporation". Ihde (1990) would say that the technology lacked "transparency" here. But it is well possible that a better design of the prosthesis, a tailor-made one instead of a ready-to-wear one, would provide a higher degree of transparency, and could thus bring about the incorporation of the device. This implies that with respect to the usage of a prosthetic device in the process of getting used to physical loss and change, the phenomenological concept of incorporation is still applicable. To comprehend the other two registers of habituation (i.e., (b) deliberately attending to the scar, and (c) sharing and displaying the scar) the concept of incorporation is too limited, however. These aspects of habituation rest on a process of "de-signifying". 


\section{Habituation as De-signifying}

Ann said that her perception of her scar, like her perception of another woman's scar changed in the sense that she managed to perceive it as something integrated into her body. She literally said: "I do no longer mention it; I mean specifically, that the breast is no longer there. Well you do mention it, but not in the sense that it concerns me, in that way". Her narrated account includes the apparent contradiction between "I mention it" and "I do no longer mention it". If we follow her statement that she does no longer mention it, we could be inclined to explain this change in perception in a way that is similar to Merleau-Ponty's description of the blind man's stick that ceases being an object of perception, for, indeed, at that moment the blind man does no longer mention his stick. However, there is a huge difference between these two kinds of perception, and this pertains to a significant difference in ontological meaning between a tool and a scar. This difference is revealed by Ann's claim that she does no longer mention that the breast is no longer there.

Whereas the ontological meaning of a tool can be adequately described in the Heideggerian terms of "being present at hand" (Vorhandensein) and "being readyat-hand" (Zuhandensein) a scar's ontological meaning needs another description. As I see it, it should be related to the ontological status of a sign. If a sign signifies something, the sign is in actual fact not perceived as something visible in itself, but as "a window through which we look at that which it signifies" (Levinas 1982: 21). Indeed, reading signs presupposes a typical way of intentionality, since the meaning we attach to a sign is not present in its given materiality. When we are reading a novel we are directed to the story. If, by contrast, we would just stick to the material givenness of the letters in the book, we will not grasp the meaning of the story. In a similar vein, the given materiality of a painting does not "resemble anything" (Marion 1991: 19); it is only by means of being directed beyond its given materiality that the meaning of the painting appears. If we apply this to Ann's experience, we can say that at the moment when she still mentioned the scar but did no longer mention the breast's absence, a rupture occurred in attributing a meaning to the scar beyond its given materiality. At that very moment, the scar stopped being a sign that refers to something else or, to use Emmanuel Levinas' metaphor, we could say that the scar stopped being a window through which Ann looked at her absent breast. The apparent contradiction between "I no longer mention it" and "I mention it" could thus be explained in terms that she did no longer mention the scar as a signifier of her loss, or that she did no longer look through her scar, but that she just looked at it and that it was the scar's own visible appearance, its materiality, that she still mentioned.

To understand this change in experience, Ihde's concept of transparency is no longer applicable. Whereas the scar first functioned as a sign that referred to something else - the absent breast—it subsequently materialized itself as something visible in itself. Hence, instead of a shift toward transparency Ann's habituation to her scar goes together with a shift toward the impenetrability of the scar's visibility. Seen in this light, also Leder's notions of absence and disappearance need refinement. If Ann succeeded in habituating to her scar, this is not because the scar 
disappeared or became absent. More likely, she habituated to it because it lost part of its signifying power. What disappeared for Ann was not her scar, but her absent breast. For Ann the disappearance of her absent breast, indicating the diminishment of her experience of loss, was crucial in her process of getting used to her scar. ${ }^{3}$

This aspect of habituation, which I have called "de-signifying," and which is clearly distinct from incorporation, has so far not been addressed in mainstream phenomenology. The reason for this is that current phenomenology of health and illness, perhaps unwittingly, prioritizes the "absent" body, whereas the here described process of "de-signifying" involves an unremitting focus on one's material body. As I see it, phenomenology of the body should be receptive to analyzing all kinds of bodily self-experiences, including the different ways in which one's body can be present to oneself.

\section{Revisiting Current Phenomenology of Health and Illness}

Ann's case puts into question the idea that the strength of the "I can" is primarily based upon the body ceasing to be an intentional object, disappearing in the margins of one's awareness. My analysis of this case thus shows that a phenomenology of illness, disability, and disfigurement should not uncritically follow the idea that the body's taken-for-granted nature-its being healthy, sane, and able-is necessarily linked to disembodying the embodied subject as much as possible. Ann resumed her bodily taken-for-grantedness while explicitly attending to her body. This designifying stance, however, did not result in her body re-appearing as an intentional object (as was the case in the instances of unsuccessful incorporation of the prosthesis). The experience of the disappearance of the lost breast rather involves Ann's material body without reference to something else. Hence, in the designifying stance, the body is present, but not present as an intentional object, it is neither just Leib, nor just Körper. I would therefore call it a Leibkörper. This typical experience of one's own body can be explained while drawing on Jean-Luc Nancy's concept of "corpus" (2008, 2013).

Although Nancy's philosophy intersects with Husserl's and Merleau-Ponty's phenomenological analyses of embodiment (Derrida 2005), their ideas diverge at several crucial points. One such point is phenomenology's implicit presumed idea of “interiority". Nancy argues that Husserl's and Merleau-Ponty's famous analyses of touch managed to put embodiment on the philosophical agenda indeed. Yet, at the same time they do not allow for the physicality and materiality involved in this

\footnotetext{
${ }^{3}$ I would like to stress here that this "disappearance of the absent breast" is based upon the scar's visibility, not on changing sensations in the breast. In that sense, this part of the habituation process should be sharply distinguished from aspects of habituation that are related to disappearing breast phantom sensations. It is well-known that phantom sensations often occur after mastectomy (Baron et al. 2007). These sensations produce the experience as if the absent amputated breast is still present. Disappearance of these sensations therefore also goes together with the disappearance of the "absent" breast. According to the Merleau-Pontian (1945) explanation of phantom experiences, we could say that this kind of disappearance refers to the fact that the absent phantom breast is no longer part of the body schema. The disappearance of the absent breast such as experienced and reported by Ann is of a different order, and for this reason it could not be explained in terms of body schema adaptation.
} 
phenomenon. To touch oneself or to be touched presumes, according to Nancy, that the body is extended, that it is outside itself. Husserl's and Merleau-Ponty's analyses of touch (as examples of localized sensations) lead, as I have discussed above, to the idea of the Leib, as an embodied, yet virtually unnoticeable, subject. Because the Leib involves an almost intangible and immaterial form of embodiment, Nancy claims that the phenomenological analyses of touch "return to a primary interiority," ignoring the body's exteriority. ${ }^{4}$ For Nancy this forms a clear contradiction: "To begin with, I have to be in exteriority in order to touch myself" (2008: 128).

While underlining that a body always implies extension and thus being exposed to something else than itself, Nancy embraces a materialist position. However, he makes it very clear that the body's matter is "sensing matter": "the body senses and is sensed" (2008: 127). In another text he describes this double-sidedness (sensing and being sensed) as "difference," which prevents matter from being an enclosed, immanent substance (Nancy 1993: 57). When the material body is no longer sensing; when it loses its receptivity or it becomes an enclosed and indifferent mass. Being a body thus implies experiencing one's body, and experiencing one's body requires being extended and exposed-and thus being material.

It is this "being material" that appears at the moment Ann attentively attends to her scar. While discussing the meaning of the body with regard to its potential signifying power, Nancy claims that we should think of the body as that which takes place at the limit of matter and sense; it is "neither a 'signifier' nor a 'signified"” (2008: 25). After no longer seeing her scar as a sign which refers to her absent breast, Ann's material scar has become this place between matter and sense. As an integral part of her changed body, the scar has no other sense or meaning than that of a feature belonging to her material body. She habituated to it while deliberately looking at it and touching it (together with her husband). This aspect of habituation to her scar took place not in spite of but owing to its ineffaceable visibility and material presence.

As I have demonstrated elsewhere (Slatman 2014b), if phenomenology of health and illness wants to do justice to patients' lived bodily experiences, it should not focus on Leib-experiences only. Phenomenology has the potential to articulate multiple dimensions of embodiment. Ann's case teaches us that next to the dimensions of Körper and Leib we must also pay attention to the dimension of the (virtually disembodied) Leib's Verkörperung. I thus propose that phenomenology of health and illness could broaden its scope if it embraces a materialist stance. If we translate this theoretical suggestion to everyday practices, it means that in order to reunite the patient into a "liveable relation" with her body (Van Manen 1998) phenomenologically oriented nursing should not only take care of alleviating experiences of bodily discomfort and alienation to such an extent that one may totally forget about one's body. Ann's case shows that such a liveable relation with

\footnotetext{
${ }^{4}$ It is disputable whether Nancy's critique of mainstream phenomenology does full justice to the works of Husserl and Merleau-Ponty. As I have explained in detail elsewhere (Slatman 2014a, Ch. 4 \& 5), especially Merleau-Ponty's later work shows more similarities than differences with respect to Nancy's way of conceptualizing the body. Since the aim of this paper is rather to make explicit a shift toward materialism in phenomenology than to evaluate various philosophers, I will not engage in a detailed comparative reading here.
} 
her body can also be the result of bringing the scarred material body in the focus of her attention.

On the basis of this single case, obviously, we cannot draw any conclusions about a general beneficial effect of active attending to one's scar. Whether other women who have to undergo a mastectomy will also benefit from actively looking at and touching their scar, or whether they should be advised to do so, remains an open question. My descriptive analysis of this single case is not meant to contribute to concrete prescriptions. Yet, it does reveal a guiding principle for habituation to physical loss and change: facing one's body's materiality. If one manages to face one's scar's materiality and expeausition, instead of reading the scar as a sign, one comes closer to identifying with one's own changed material body. ${ }^{5}$ The marks that tell "the story of who we are" (Auster 2012: 5) should also be seen as actual parts of what and who we are.

Since we habitually attribute much signifying power to bodies, body parts (the female breast in particular), and bodily marks, it is not at all obvious to simply stop "reading" one's own body and its marks. However, I certainly believe that a focus on the body's materiality - comparable perhaps to the focus on a painting's materialityhelps to "de-signify" it. It helps to erase or "exscribe," as Nancy (2008: 9) would say, the immaterial signified beyond the material. I started this paper with the observation that there is no agreement about what mastectomied women should do in order to get habituated to their changed body - whether they should conceal it or not, whether they should take a tattoo (Langellier 2001), or perhaps even whether they should actively share and display their scar, make pictures of it (Martin and Spence 1985). To assess the degree to which these various interventions may help women to habituate to their scars, we need to further explore in what sense and under which conditions these interventions can actually play a role in returning to materiality.

Acknowledgments First of all I would like to thank Ann for sharing her story with me. A first version of this paper has been presented at the Center for Contemporary European Philosophy at Radboud University, Nijmegen at 22 May 2014. I would like to thank Chantal Bax and Katrine Smiet for their stimulating questions. Also thanks to two anonymous reviewers.

Funding This study was funded by the Netherlands Organization for Scientific Research (NWO-VIDI276-20-016).

\section{Compliance with Ethical Standards}

Conflict of interest The author declares that she has no conflict of interest.

Open Access This article is distributed under the terms of the Creative Commons Attribution 4.0 International License (http://creativecommons.org/licenses/by/4.0/), which permits unrestricted use, distribution, and reproduction in any medium, provided you give appropriate credit to the original author(s) and the source, provide a link to the Creative Commons license, and indicate if changes were made.

\footnotetext{
5 Nancy introduces the French term expeausition (skin-show), playing with the similar phonetics of "po" and "peau" (skin), to describe the body's fundamental being outside itself, or its exteriority (2008: 32f.).
} 


\section{References}

Ahmed, S. (2006). Queer phenomenology: Orientations, objects, others. Durham and London: Duke University Press.

Aho, J., \& Aho, K. (2009). Body matters: A phenomenology of sickness, disease, and illness. Lanham: Lexington Books.

Auster, P. (2012). Winter journal. New York: Henry Holt and Co.

Baron, R. H., Fey, J. V., Borgen, P. I., Stempel, M. M., Hardick, K. R., \& Van Zee, K. J. (2007). Eighteen sensations after breast cancer surgery: a 5-year comparison of sentinel lymph node biopsy and axillary lymph node dissection. Annals of Surgical Oncology, 14(5), 1653-1661.

Bullington, J. (2013). The expression of the psychosomatic body from a phenomenological perspective. Berlin and Heidelberg: Springer.

Campbell, C. S., Clark, L. A., Loy, D., Keenan, J. F., Matthews, K., Winograd, T., et al. (2007). The bodily incorporation of mechanical devices: Ethical and religious issues (part 1). Cambridge Quarterly of Healthcare Ethics, 16(02), 229-239.

Carel, H. (2011). Phenomenology and its application in medicine. Theoretical Medicine and Bioethics, 32(1), 33-46.

Carijó, F. H., de Almeida, M. C., \& Kastrup, V. (2013). On haptic and motor incorporation of tools and other objects. Phenomenology and the Cognitive Sciences, 12(4), 685-701.

De Preester, H. (2011). Technology and the body: The (im) possibilities of re-embodiment. Foundations of Science, 16(2-3), 119-137.

De Preester, H., \& Tsakiris, M. (2009). Body-extension versus body-incorporation: Is there a need for a body-model? Phenomenology and the Cognitive Sciences, 8(3), 307-319.

Derrida, J. (2005). On touching, Jean-Luc Nancy (C. Irizarry, Trans.). Stanford: Stanford University Press.

Dreyfus, H. L. (2002). Intelligence without representation-Merleau-Ponty's critique of mental representation. Phenomenology and The Cognitive Sciences, 1(4), 367-383.

Friedeberger, J. (1996). The false breast: Should we go for it so quickly? BMJ, 313(7063), 1014-1015.

Goffman, E. (1963). Stigma. Notes on the management of spoiled identity. New York, London, Toronto: Simin and Schuster.

Heidegger, M. (1927). Sein und Zeit. Tübingen: Max Niemeyer Verlag.

Husserl, E. (1952). Ideas pertaining to a pure phenomenology and to phenomenological philosophy. Second book (R. Rojcewicz, A. Schuwer, 1989, Trans.). Dordrecht: Kluwer Academic Publishers.

Ihde, D. (1990). Technology and the lifeworld. From garden to earth. Bloomington and Indianapolis: Indiana University Press.

Langellier, K. M. (2001). You're marked: Breast cancer, tattoo and the narrative performance of identity. In J. Brockmeier \& D. Carbaugh (Eds.), Narrative and identity: Studies in autobiography, self, and culture (pp. 145-184). Amsterdam: John Benjamins Publishing.

Leder, D. (1990). The absent body. Chicago: University of Chicago Press.

Leder, D. (1992). A tale of two bodies. The Cartesian corpse and the lived body. In D. Leder (Ed.), The body in medical thought and practice. Dordrecht: Kluwer Academic Publishers.

Levinas, E. (1982). En découvrant l'existence avec Husserl et Heidegger: Suivi d'Essais nouveaux. Paris: Vrin.

Lorde, A. (1980). The cancer journals. San Francisco: Spinsters, Aunt Lute.

Manderson, L. (2011). Surface tensions: Surgery, bodily boundaries, and the social self. Walnut Creek, CA: Left Coast Press.

Manderson, L., \& Stirling, L. (2007). The absent breast: Speaking of the mastectomied body. Feminism and Psychology, 17(1), 75-92.

Marion, J.-L. (1991). La Croisée du visible. Paris: Presses Universitaires de France.

Martin, R., \& Spence, J. (1985). New portraits for old: The use of the camera in therapy. Feminist Review, 19, 66-92.

Martiny, K. M. (2015). How to develop a phenomenological model of disability. Medicine, Health Care and Philosophy,. doi:10.1007/s11019-11015-19625-x.

Merleau-Ponty, M. (1945). Phenomenology of perception (C. Smith, 1962, Trans.). London and New York: Routledge.

Morris, D. (2002). Touching intelligence. Journal of the Philosophy of Sport, 29(2), 149-162. 
Murray, C. D. (2004). An interpretative phenomenological analysis of the embodiment of artificial limbs. Disability and Rehabilitation, 26(16), 963-973.

Nancy, J.-L. (1993). The sense of the world (J. S. Librett, 1997, Trans.). Minneapolis: University of Minnesota Press.

Nancy, J.-L. (2008). Corpus (R. A. Rand, Trans.). New York: Fordham University Press.

Nancy, J.-L. (2013). Corpus II. Writings on sexuality (A. O’Byrne, Trans.). New York: Fordham Press.

Sartre, J.-P. (1943). Being and nothingness. An essay on phenomenological ontology. (H. E. Barnes, 2007, Trans.). London and New York: Routledge.

Slatman, J. (2014a). Our strange body. Philosophical reflections on identity and medical interventions. Amsterdam: Amsterdam University Press.

Slatman, J. (2014b). Multiple dimensions of embodiment in medical practices. Medicine, Health Care and Philosophy, 17(4), 549-557.

Slatman, J., Halsema, A., \& Meershoek, A. (2015). Responding to scars after breast surgery. Qualitative Health Research. doi:10.1177/1049732315591146.

Svenaeus, F. (2009). The phenomenology of falling ill: An explication, critique and improvement of Sartre's theory of embodiment and alienation. Human Studies, 32(1), 53-66.

Toombs, S. K. (1995). The lived experience of disability. Human Studies, 18(1), 9-23.

Ucok, O. (2005). The meaning of appearance in surviving breast cancer. Human Studies, 28(3), 291-316.

Van Manen, M. (1998). Modalities of body experience in illness and health. Qualitative Health Research, $8(1), 7-24$.

Waldenfels, B. (1989). Körper-Leib. In J. Leenhardt \& R. Picht (Eds.), Esprit/Geist. 100 Schlüsselbegriffe für Deutsche und Franzosen. Piper: München.

Williams, S. J. (1996). The vicissitudes of embodiment across the chronic illness trajectory. Body and Society, 2(2), 23-47.

Young, I. M. (1992). Breasted experience: The look and the feeling. In D. Leder (Ed.), The body in medical thought and practice (pp. 215-231). Dordrecht: Kluwer.

Zaner, R. M. (1981). The context of self: A phenomenological inquiry using medicine as a clue. Athens, $\mathrm{OH}$ : Ohio University Press.

Zeiler, K. (2013). A phenomenology of excorporation, bodily alienation, and resistance: Rethinking sexed and racialized embodiment. Hypatia, 28(1), 69-84. 